\title{
Society's expectations of health
}

\author{
Edmund Leach King's College, Cambridge
}

Sir Edmund Leach argues that doctors in the modern world, fortified by the traditional concept that the life of the sick person must at all costs be preserved, are to some extent guilty of the false antitheses current today between youth and age. Moreover youth means health, age illness and senility. Until this im-

balance is corrected society will be in danger of ' $a$ kind of civil war between the generations'. Society must be taught again that mortality cannot be avoided or conquered by medical science, and at the same time that 'health' is not enshrined in the young alone.

I speak as a layman and not as a doctor but after the nitty-gritty, down-to-earth approach of all the previous speakers in today's proceedings I fear that I must appear very much as a characteristic specimen of Belloc's 'remote and ineffectual don'.

\section{Ideas of health and sickness}

I am not talking about facts at all but about subliminal ideas; ideas which are felt rather than expressed, but which influence the things that we actually say and do.

Regrettably, but undeniably, 'good health' is a negative idea. If I sprain my ankle I am ill and I complain of the fact; when I walk without a limp I take my good health quite for granted. And so it is with all forms of illness and physical disability. 'Good health' is a synonym for normality: 'illness' for abnormality. But there are many kinds of abnormality. Any injury or disease which threatens death is an 'illness', but so also is menstruation and so also, after a fashion, is pregnancy. ${ }^{1}$

My point here is that our attitudes to illness and good health are ambiguous. On the one hand physical abnormality is surrounded by a penumbra of danger

\footnotetext{
${ }^{1}$ A century ago these attitudes were much more freely expressed than they are now. In 1871 a Dr W C Taylor in his $A$ physician's counsels to women in health and disease recommended: "We cannot too emphatically urge the importance of regarding these monthly returns as periods of ill health... every woman should look upon herself as an invalid once a month'. A pregnant woman was 'indisposed'; menopause was the 'death of the woman in the woman'. (Quoted in B. Ehrenreich and D. English Complaints and disorders: The sexual politics of sickness Glass Mountain Pamphlet no 2, p 21, London: Compendium.)
}

and religious mystery; on the other it is a marker of the ongoing progression of life. The periodicity of female 'illness' is society's basic clock.

\section{Death as well as birth a social necessity}

In a fundamental biological sense, human societies exist because the young of the species Homo Sapiens matures slowly. If the species is to survive, human children must be nurtured and protected and socialized in an adult context for at least the first Is years of their existence. The procreation and rearing of children is thus the focal point of domestic life in every human society everywhere. But this lifecentred activity presupposes a corresponding mortality. Any sustained excess of deaths over births is self evidently destructive to the fabric of society; but so also is any sustained excess of births over deaths. Death as well as birth is a social necessity. It is your cardinal sin as a medical profession that you have almost persuaded the general public that this is not the case. ${ }^{2}$

Perhaps I should not blame the doctors. Even in primitive societies birth is welcome, death is feared and regretted. Yet at some psychologically repressed level, we are all well aware that these two biological phenomena are interdependent. Religious dogma repeatedly asserts that death is only a rebirth into another mode of life; social initiations of all kinds, the rituals which anthropologists describe as 'rites of passage', are regularly found to incorporate the same binary symbolism - the initiate 'dies' in one role and is 'reborn' into another.

\section{Social treatment of the sick}

The symbolic treatment of initiates is very like our social treatment of the sick. It is also very like

${ }^{2}$ Clearly we must all die sooner or later but as the medical profession has step by step eliminated the major killer diseases of the past - plague, typhus, typhoid, smallpox, diphtheria, tuberculosis ... other ailments necessarily come to be seen as the principal enemies of life. Today vast resources are devoted to the elimination of cancer and heart disease. What next? The doctors of course know very well that it is all ultimately of no avail but the public is certainly given the impression that if only they spend enough money they will eventually be granted immortality. 
our social treatment of criminals. This points to the fact that our attitude towards both these classes of persons is powerfully influenced by irrational (symbolic) considerations. Those who are rated as 'abnormal' are always isolated in a place set apart. The separation is both physical - by means of walls and locked doors - and metaphysical - by barriers of taboo, subliminal beliefs about the dangers of sanctity, and pollution.

But here again the rational and the irrational are inseparably confused. Abnormal people are distinguished from normal people either because they are polluted (excessively 'dirty' in either a physical or metaphysical sense) or because they are divinely pure (excessively 'clean'). So we find that medical procedures, whether rooted, as in the past, in magic, or, as today, in science, hover uncertainly between the removal of dirt from the polluted (washing, shaving, urine analysis, lumbar punctures, restricted diets, operative surgery) and the addition of dirt to the impotent, overpurified (medications of all kinds, blood transfusions, organ transplants). And this despite the fact that most doctors will admit, in unguarded moments, that a high proportion of all their patients would probably get on a lot better if they were simply left to their own devices.

No doubt it is entirely rational that nursing staff should seek to maintain their hospital wards in a condition of perfect cleanliness and sterility. But how irrationally appropriate! In all religious systems sexual sterility is a characteristic of the Other World. When a doctor sends his patient to hospital the polluted individual is placed in an abnormal context of excessive purity - a context of death. Normal good health is only achieved when the patient returns to a normal environment which is neither overclean nor overcontaminated, an environment in which life and sexuality rather than death and sterility are the dominating values.

\section{Good health means sexual vigour}

And that is the main thesis of this paper: subliminally the general public's idea of good health is all mixed up with ideas about sexual vigour.

The point from which I started out is central to these ambivalent social attitudes: for society at large menstruation is the prototype state of being unwell. ${ }^{3}$ And, in primitive society especially, the menstruating woman is the prototype example of the polluted person. Notice too how our concepts of health and

${ }^{3}$ This is a universal fact which has had an influence on the development of medical practice. In primitive society the monthly illness of menstruation is the only form of illness which can regularly be relied upon to cure itself. The cure comes about following a flow of blood. In imitation of this fact, doctors have persuaded themselves that artificially induced bleeding will have curative effects on all kinds of illness. Leechcraft based on this sex mesh in with ideas of religious and ethical value Consider for example the following pairs of terms? healthy/sick; potent/impotent; profane/sacred; un holy/holy; good/evil; pure/polluted; ascetic/ecstatie: The point I want to make is that in considering th precise relationship between these pairs of terms we quickly see that each binary pair may be turneff upside down without affecting the principle that each of these oppositions is somehow a 'trans formation' of every other. Let me illustrate this rather abstract proposition.

In the religions of India there are two modes $0 \vec{\Phi}$ achieving salvation: through exceptional sanctity and religious potency. Both modes are represented iff present-day religious practice as well as in the mythology recorded in the ancient texts and ip classical works of Indian art. The one mode calls for a total asceticism, a passive cleanliness and complete abstention from every form of sexuay activity; the other calls for violent erotic ecstacy and exaggerated sexual indulgence. Normal virtue in the high caste Hindu moral code calls for compromise between these two extremes. Sexuat. excess is a vice; sexual potency and the reproduction of children is a duty.

I have mentioned the Indian case because the polarity of values is there particularly clear cut bue similar ambiguities are to be met with in manţ European contexts. Notice for example the parados whereby a virtuous Roman Catholic priest is required to be celibate, whereas a virtuous Roman Catholic married woman is required to bear children 3 The point of quoting such examples for mys present purposes is simply this: while health goes with salvation (virtue) ${ }^{4}$ and sickness with sin (evil) the distinction must always be viewed in context We constantly shift our ideas about what constituteso good or evil, health or sickness, according to the status and social condition of the individual undero consideration. Ill health cannot be quantified; it is not a specific condition; it is an idea. 5

Contrasts between health and disease - beauty $\frac{7}{0}$ 隹
and ugliness

One of the oppositions which most closely resembles 0 that between health and sickness is the contrast $t_{\omega}^{N}$ theory has only very recently been eliminated from western medicine. Medical procedures based on purga- $-\frac{\mathrm{C}}{\Phi}$ tion of the bowels are also metaphorically associated $\mathbb{D}$ with the self-evident curative effect of menstruation.

${ }^{4}$ As Dr Illich remarked, salud in Spanish means both health and salvation.

'To judge from the medical papers and the discussion, $\frac{\mathcal{P}}{\mathbb{P}}$ this relativist view of illness is quite foreign to the thinking of most of those attending the conference,, nearly all of whom seemed to assume that 'illness' couldo be quantified as the number of cases listed in the fileso of general practitioners and hospitals under a finite taxonomic set of named diseases or physical defects. 
between beauty and ugliness. The healthy body is beautiful, the sick body is repellent. But here again we immediately run into moral uncertainty. Concepts of beauty vary with fashion and cultural convention but they are always heavily loaded with sexual value. Moral conventions concerning sex influence our ideas of physical beauty and hence our ideas about good health.

In this regard, changes in artistic fashion reflect corresponding shifts in social attitudes towards sex and procreation. For example, there have been times and circumstances in which beautiful women were regularly portrayed as pregnant. On the other hand, in mid-Victorian England, although working class women were presumed to have the strength of carthorses, women in polite society were thought of as frail and delicate invalids. There were sculptors working at the time of the Great Exhibition of $185 \mathrm{I}$ who managed to produce figures of naked women in white marble which were entirely devoid of sexuality. Several remarkable examples can be seen in the antechamber rooms of Buckingham Palace which are open to the public. It is difficult to say just what is wrong with them; they certainly are not pregnant; but to a twentieth century eye they look very sick indeed!

Similar oscillations of taste have influenced our social conception of the healthy male. The art and mythology of classical Greece may seem rather remote from the theme of this conference but it has medical significance. The classical representations of Hermes, son of Zeus, illustrate my point rather well. At first all the emphasis was on sexual virility. The sculptured image was reduced to a rectangular block surmounted by a bearded adult head with an erect penis in front. At this stage Hermes was an expression of the creative potency of God directly comparable to the lingam as an expression of the potency of Shiva. Later, Hermes became an adult male athlete, a sort of Hollywood film star of the silent film epoch, a type which the English popular press still seems to regard as the prototype of a healthy handsome man. Finally Hermes appears as a beautiful adolescent boy, an object of sterile homosexual interest rather than of fertility.

In his adult athlete form Hermes was described as 'the messenger of the gods' and was endowed with many of the attributes of Apollo, including the power of healing. Although a notorious cheat he was certainly seen as benevolent, a very proper patron saint of doctors! But in his final catamite manifestation Hermes is the Herald of the Underworld who conducts the souls of the dead to Hades. All too appropriately, though no doubt in error, the American medical profession has adopted the caduceus, the winged staff with intertwined serpents, as their official emblem. The caduceus, in this form, was Hermes' staff of office in his capacity as herald of death. But the point I want to emphasize is that in classical art, even when Hermes had become the emissary of death, he continued to epitomize male beauty but by this time his form had been changed from that of a virile youth to that of a sterile boy.

While you are reflecting on the conscious or subconscious implications of such shifts of value, let me say something more about those intertwined serpents. The emblem of the American medical profession is no doubt intended to be the symbol of Asclepius, the Greek god of medicine whose real symbol was entirely phallic, a single serpent coiled around a free, as in the Garden of Eden. But Asclepius was just as ambiguous in his moral nature as was Hermes. His medical powers were derived from two phials of blood drawn from the body of the Gorgon. The blood from the right side produced an instant cure; that from the left side caused instant death. There was, however, some uncertainty about which phial was which. The Greeks had no illusions about their doctors' professional competence.

All this is no doubt very much by the way; yet such trivia of art and mythology certainly bear on my general theme. If our prototype of a healthy man is a young, virile athlete, then all elderly figures will seem unhealthy. If on the other hand the male ideal is based on the figure of a veteran in his 605 then all elderly males will appear normal. The pattern will be different again if the ideal of male beauty is an adolescent boy. The same point can be made about images of female beauty. There must surely be something very odd about our own society in which the specimens of female pulchritude who display their charms in the Miss World beauty contest have an average age around 20 whereas the average female in the society at large is probably well past the menopause. An aging society which continues to search for the elixir of youth will necessarily persuade itself that it is already approaching the final stages of senility.

And for this state of affairs the medical profession carries a heavy load of responsibility.

\section{Demographic patterns in modern society}

Let me remind you of a fundamental demographic phenomenon. In all modern industrial countries which have an advanced, well financed medical service the expectation of life of all infants born alive is now approaching 75 years. In most cases it is less than a century since the expectation of life was about 40 years. ${ }^{6}$

The social consequences of such changes will depend upon many factors, including changes in

${ }^{6}$ At the present time the figures for USA, UK, USSR, Japan, France, the Netherlands are all very similar. In these countries life expectancy for males ranges from 65 (USSR) to 71 (Netherlands) and for females from 73 (USSR, Japan, USA) to 75 (France). Around 1850 the figures for the USA and UK were males 38-40; females 40-42. 
the birth rate, changes in educational practice, changes in conventions regarding age of retirement, but in some cases they may be very striking. For example in the United States and the Netherlands the birth rate during the period 1945-1960 was such that in 1960 rather over 30 per cent of the population was under 15 . Since then the birth rate in these countries has fallen quite sharply and it seems likely that by the year 2000 over one-third of the population will be over 60 . The pattern in Britain has been different but even so, if the birthrate continues on its present downward trend and the average age at which education is completed continues to rise, and we preserve our present conventions regarding retirement and rights to a pension, we must envisage that before very long, at least for a substantial period of years, around one-third of the surviving population of many advanced countries (including this one) will be in the status of old age pensioners, while the productive labour force of the nation may be substantially less than a quarter of the total population.

I do not think that things will work out like that; the more vigorous members of the population will not, in practice, allow themselves to be exploited by their elders in this way. But medical attitudes towards life and death, and public attitudes which discriminate healthy youth from unhealthy age, will both have to shift quite drastically if a kind of civil war between the generations is to be avoided. Let me spell out more explicitly what I have in mind.

The methods of modern medicine purport to be scientific and, despite the scepticism of some contributors to this conference, the claim is justified. In part at least, modern medicine is based on a sophisticated understanding of biochemical processes; medicine is no longer just a mixture of magic, optimism and experience. This state of affairs is very new. Much less than a century ago the act of summoning a doctor was a ritual of last resort, an appeal to magic rather than to science. Admittedly the patients sometimes survived but this was a tribute to human physique rather than to medical skill. Traditionally, in the world at large, medicine has been an art which was developed as a magical means of postponing death. The basic opposition is not between health and sickness but between life and death.

\section{The doctor's duty to postpone death}

Even today it is a fundamental principle of medical ethics that every doctor has an absolute duty to do everything possible to postpone death even when there is no prospect at all that the patient could ever again enjoy a state of existence remotely resembling 'good health' - however defined. No doubt there are many doctors who are prepared to qualify the strict terms of this particular ethical principle in the interests of mercy but the official code is quite unambiguous and is supported b९ the law. In the past, this made sense. Doctors were able to make an inflexible dogma out of their duty to save life because, in practice, the dogma had verif little real consequence. So long as medical practice remained an art rather than a science its function was essentially palliative. It was a form of witc doctoring. It could bring reassurance to the patient and to the patient's relatives but it coulक not significantly alter the natural course of events But with the development, over the past 30 years? of sophisticated chemotherapy, antibiotics, bloo $\bar{\Phi}$ transfusion, etc, doctors have it in their power to keep alive, in a manifestly unhealthy condition whole classes of individuals who would quite certainly have died in the 'natural' course oo events.? The moral dilemmas which thereb $\vec{y}$ ensue are very familiar to everyone in this room: do do not get the impression that anyone knows how to deal with them.

You need to appreciate that in the past most ordinary human beings experienced illness as at episode of relatively short duration. The sick individual either died or recovered. Only a fere people in the upper classes of a few affluent societies? could afford the luxury of the invalid state implie by enduring illness or senility. In such circum乏 stances the negative attitude to health which $\overline{5}$ remarked upon right at the beginning made goog sense. Anyone who was not ill was active, norma and healthy, and since most people were quite young, the young athlete made a sensible ideal.

\section{The doctor's responsibility for the age structure of modern society}

But today medical science, by its drastic reduction of mortality among children and mothers and young. adults generally, has generated a very large clase of aging individuals who are no longer young, fulle active, and 'healthy' in the traditional sense, bue who are not 'ill' in the traditional sense either. On the contrary they are often exceedingly fit in qualified sort of way. But because society's idea of health still has a strong sexual component, our modeP of the healthy individual is of a young man of woman in the prime of sexual life. If you doubt this just reflect on the images served up to us in maga-o zine advertisements and TV commercials. Against this background the 'senior citizen' whose sexuaf vigour is declining even though he is physically? competent in nearly all other respects is liable to geto written off as no longer really healthy!

7This of course is a matter which arouses strong passions $\frac{\rho}{10}$ My personal opinion is that it is fundamentally immorale that doctors should use their skills to keep alive the following classes of individuals: infants born witho serious congenital defects, individuals who haveo suffered serious brain damage as a result of accident, old $\leq$ people approaching senility who suffer a serious illness $\frac{\sqrt{2}}{?}$ 
Indeed all elderly people tend to be lumped in together and treated with the cloying sympathy appropriate to cripples in wheeled chairs. No, that is an exaggeration. I should have said all retired, elderly people. The inconsistencies here are very notable. Officers and men in the Armed Forces, who are likely to be among the fittest members of their generation, are often compulsorily retired in their $40 s$ on the theory that their health is failing; likewise most civil servants are compulsorily retired at 60. In contrast, politicians, judges, and business magnates are allowed to hang on to power almost indefinitely.

The reason is obvious. Society has not yet devised a status for the elderly which carries with it both dignity and active responsibility into which men of power will voluntarily transfer themselves. At present the only alternative to the career of active youth is the non-career of 'retirement', so, at present, all varieties of 'retirement' carry the stigma of a presumed actual or impending illness. Consequently most people will only enter that status if they are compelled to do so.

This is a serious matter. Around the year 1800 virtually all the political leaders of Europe were under 35 ; in recent years the average age of such men of influence has been nearer 70 ; in a number of notorious cases they have become completely senile while still holding office.

Some years ago I achieved a certain notoriety by suggesting that everyone in a position of power or influence should be compelled to give up office around the age of 45 . I would still argue that way. But a reform of that sort will never become plausible until society has come to terms with the fact that the individual no longer has any reason to expect to be dead before he or she is 55 .

A normal life span of something between 70 and
80 years is with us to stay. Society must adjust itself accordingly. Common sense suggests that it should be normal to expect at least a two-phase career. A first career for the young and ultravigorous (who should be the active wielders of power) and a second career of genuine responsibility for older people who are still perfectly active but are not asked to measure their standards of health and vigour against swimming champions and track runners in accordance with the value system of ancient Sparta. I am serious about that. Despite the obvious discrepancy from reality, the model of ideal good health which ordinary members of the public pick up, through the visual images of the Press and the TV screen and from the verbal suggestions of their doctors, is closely related to the classical ideal of the youthful Greek athlete.

The general consequence, I suggest, is to persuade the great majority of individuals that they are hopelessly inadequate, physically, sexually, and in every other way.

As the average age of the population gets older, the romantic image of youth and beauty becomes more and more remote and the popular stereotype of youthful good health becomes less and less attainable. But we cannot really escape reality whatever the drug companies may say. The elixir of perpetual youth is not obtainable on doctor's prescription. The doctors, in their all too successful efforts to postpone the onset of mortality, have persuaded many of their patients that if only we devote enough of our national resources to the development of medicine it will in the end be possible to avoid death altogether. But the nett effect of such delusions has been to intensify anxiety; by their very success the doctors have converted a large sector of the population into querulous invalids. 